\title{
Hyoscine Butylbromide and the Duration of Labor: A Systematic Review and Meta-Analysis Study
}

\author{
Mehdi Ranjbaran $^{1,2}{ }^{\circledR}$, Reza Omani Samani ${ }^{*{ }^{\circledR}}$, Maryam Hafezi ${ }^{3}$, Kamyar Mansori ${ }^{4,5}$, Nader Mahdavi ${ }^{6}$, \\ Hebteyes Hailu Tola ${ }^{7}$
}

\begin{abstract}
Objectives: Hyoscine butylbromide is one of the drugs that is used to shorten prolonged labor and helps to decrease the complications and pain related to prolonged labor. To prescribe this drug, understanding its effect on the duration of labor is important through summarizing the available primary study results. Therefore, the present study aimed to determine the effect of hyoscine butylbromide in shortening the duration of labor through summarizing the available primary evidence.

Materials and Methods: To this end, different electronic databases were searched including the International Scientific Indexing Web of Science, PubMed/Medline, and Scopus in order to find English published articles during 2000-2017. The obtained data were by Stata software. Finally, the effect of hyoscine butylbromide was estimated by the mean difference (MD) and CI as the summary measures using a random-effects meta-analysis model.

Results: Based on the results, hyoscine butylbromide significantly reduced the duration of labor in the intervention group when compared to the placebo group in the first $(\mathrm{MD}=-67.77$ minutes, $95 \% \mathrm{CI},-90.98$ to -44.56$)$ and second stages of labor $(\mathrm{MD}=-2.76$ minutes, $95 \% \mathrm{CI},-4.79$ to -0.74$)$. However, it failed to significantly decrease the duration of labor in the third stage (MD $=-0.45$ minutes, $95 \% \mathrm{CI},-1.45$ to 0.56 ) in the intervention group.

Conclusions: In general, hyoscine butylbromide led to a significant reduction in the duration of labor in the first and second stages while it caused no significant decrease in its duration in the third stage. Thus, hyoscine butylbromide could be used for reducing labor duration in the first and second stages of delivery.

Keywords: Hyoscine-N-butylbromide, Labor, Obstetric, Labor onset
\end{abstract}

\section{Introduction}

Prolonged labor and related complications are among the risk factors that affect pregnancy outcome. In addition, it is considered as the main factor which increases maternal and fetal complications and one of the most important factors that encourages pregnant women to deliver through cesarean section $(1,2)$. Further, prolonged labor has several main neonatal and maternal outcomes including episiotomy usage, chorioamnionitis, postpartum hemorrhage, operative delivery, perineal trauma, birth depression, low Apgar score, more hospitalization in the neonatal intensive care unit, and increased maternal morbidity (2-4).

Different drugs are used to shorten prolonged labor duration and pain related to labor $(5,6)$ including hyoscine butylbromide, which is an antispasmodic drug that is often used to induce or increase the cervical contraction, leading to a decrease in the duration of labor (7). Furthermore, this drug directly exerts an effect on the smooth muscles of the gastrointestinal and genitourinary system (8) in order to induce contraction which results in reducing labor duration.

Despite various results regarding the effect of hyoscine butylbromide on the reduction of prolonged labor, it is widely utilized to reduce the duration of labor worldwide. However, the drugs prescribed during pregnancy and childbirth should be based on high-quality evidence and scientific documentation in order to decrease their adverse reactions. In addition, although several related studies are available in the literature and hyoscine butylbromide is extensively employed to accelerate cervical opening and the progression of labor, no overall conscience exists respecting its effect on the duration of labor. Therefore, the current study sought to investigate the effect of hyoscine butylbromide on the duration of labor by a systematic review and meta-analysis through summarizing the existing evidence. 


\section{Materials and Methods}

Search Strategies and Study Selection

Based on the aim of the study, several electronic databases such as the International Scientific Indexing Web of Science, PubMed/Medline, and Scopus were searched to obtain English articles published during 2000-2017. For this purpose, a systematic search was conducted using all possible combinations of keywords such as "Hyoscine", "Labour", and "Labor". Moreover, the search strategy used during the database search were as follows.

- The PubMed search: ("hyoscine [Title/Abstract]" AND "labor" OR "labour") OR ("Scopolamine Hydrobromide [Mesh]" AND "labor [Title/Abstract]" OR "labour [Title/Abstract]");

- The Scopus search: (TITLE-ABS-KEY (hyoscine) AND TITLE-ABS-KEY ("labor" OR "labour");

- The International Scientific Indexing Web of Science: $\mathrm{TS}=$ (hyoscine OR Scopolamine) AND TS= (labor OR labour).

It is noteworthy that the references of the included articles were reviewed as well.

\section{Inclusion and Exclusion Criteria}

All clinical trials published in English were included based on the following inclusion criteria:

- Study design: Randomized, placebo-controlled clinical trials;

- Population: Both primi- and multigravid women with term pregnancies (the results were separately reported in these two groups;

- Intervention: Hyoscine-N-butyl bromide;

- Outcome: At least one of the outcome variables including the mean duration of labor at first, second, or third stage.

Additionally, several types of studies were excluded such as the review studies, those reported before 2000, studies in which the intervention group received multiple treatments or the control group received any practice that could affect the outcomes, studies with duplicate citation, and those with reported unimportant data concerning the outcome variable that was required for meta-analysis (mean and standard deviation).

After the primary search to retrieve the potential studies, the obtained data were screened for eligibility based on their titles and abstracts, followed by assessing the fulltext articles for eligibility based on the above-mentioned inclusion criteria.

\section{Quality Assessment}

In addition, quality assessment was conducted using 8 items selected from the Consolidated Standards of Reporting Trials checklist (9) including eligibility criteria for the participants, the interventions for each group with sufficient essential details, completely defined outcome measures, the method of sample size determination, the type of randomization, allocation concealment mechanism, blinding, statistical methods of group comparison for the outcomes, and the results for each group, along with the estimated effect size and its precision. The studies were grouped as high-quality data if they met all the required criteria or failed to meet only 1 or 2 items, otherwise, they were included in the low-quality group when not meeting more than two items. Then, 2 researchers independently performed the quality assessment. Further, the guideline of the Preferred Reporting Items for Systematic Reviews and Meta-analyses statement was used for reporting the findings of this study (10).

\section{Data Extraction}

The variables that were extracted for data analysis included the author, the year of study, location, parity (i.e., primigravid/multigravid), as well as labor stage, the number of participants in each group, and the mean and standard deviation of labor duration.

\section{Statistical Analysis}

The obtained data were analyzed by Stata software, version 11 (StataCorp LP, 4905 Lakeway Drive, College Station, TX 77845, USA), and the mean difference (MD) of labor duration, along with its $95 \%$ CI was calculated as summary measures. Furthermore, the chi-square test was applied based on Q-test and $\mathrm{I}^{2}$ statistics with a significance level of $<0.1$ in order to evaluate the potential heterogeneity among the studies. The $\mathrm{I}^{2}$ statistics ranged from $0 \%-100 \%$ and the high value indicated high inconsistency among the studies (11). Moreover, the random-effects model was utilized to estimate the pooled effect based on the rejection of homogeneity hypothesis. The significance of the overall $\mathrm{MD}$ was determined by $\mathrm{Z}$ test and $P<0.05$ was considered statistically significant. Eventually, potential publication bias between the studies was assessed by the Egger's test considering $P<0.1$ as the significant level.

\section{Results}

Figure 1 depicts the PRISMA flow diagram (10) of the search strategy and the process of study selection. A total of 186 articles were retrieved by databases search while four articles were obtained by manual search. After removing duplicate citation and screening for relevancy, 22 full-text articles were assessed for eligibility, out of which 10 articles met the eligibility criteria for meta-analysis. Additionally, publications that reported the results separately in the pre-considered subgroups of the present study including the stage of labor (i.e., the first, second, or third stage), and parity (i.e., primi- and multigravid) were entered into meta-analysis as separate studies. Table 1 represents the characteristics of the included studies.

The results of chi-square Q-test and $\mathrm{I}^{2}$ statistics revealed the heterogeneity between the studies in the first $\left(\mathrm{Q}=217.71, P<0.001\right.$, and $\left.\mathrm{I}^{2}=94.0 \%\right)$, second $(\mathrm{Q}=33.01$, $P<0.001$, and $\left.\mathrm{I}^{2}=72.7 \%\right)$, and third $(\mathrm{Q}=13.89, P=0.008$, and $\left.\mathrm{I}^{2}=71.2 \%\right)$ stage of labor. 


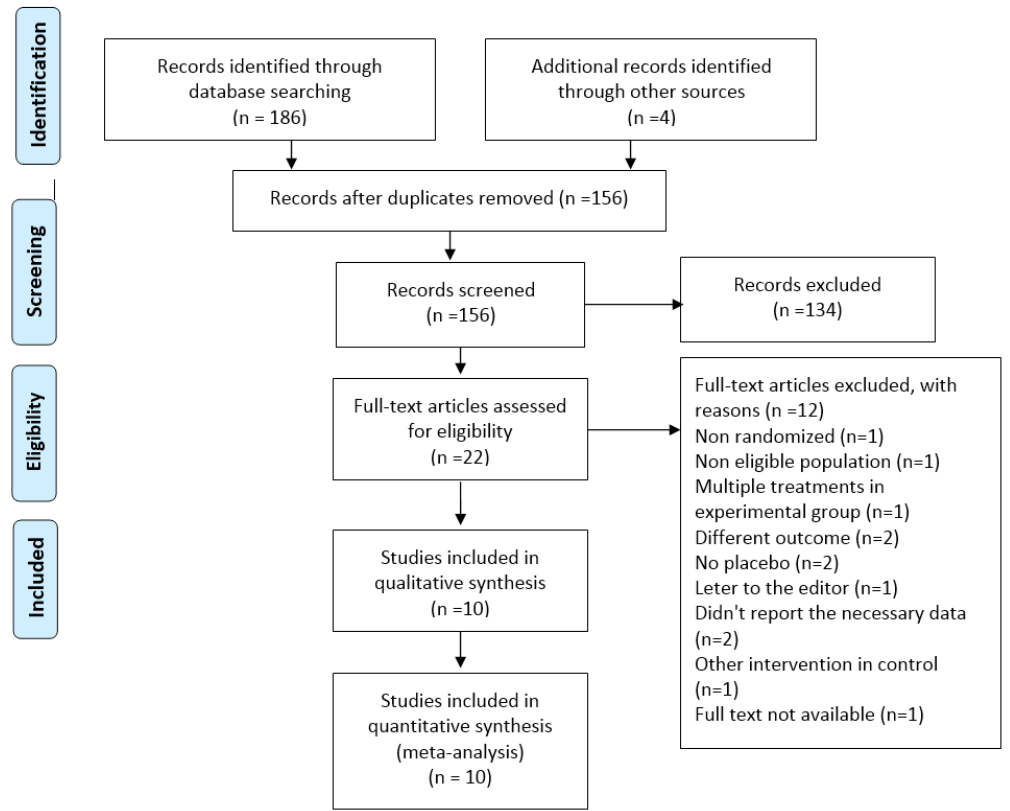

Figure 1. Flowchart for the Selection of Studies About the Effect of Hyoscine on Labor Duration.

First Stage of Labor

As shown in Figure 2, the overall effect of hyoscine on the duration of labor demonstrates a statistically significant difference between the intervention and placebo groups without considering the parity status of women $(\mathrm{MD}=-$ 67.77 minutes, CI 95\%, -90.98 to -44.56$)$. Eight out of 10 studies report the results in the first stage of labor in primigravid women while four out of 10 studies present the first-stage results in multigravid women. In addition, as regards the pooled effect estimation, the results of the meta-analysis in these subgroups show that hyoscine significantly reduces the duration of labor in the intervention group when compared to the placebo group among primigravid ( $\mathrm{MD}=-78.51$ minutes, CI 95\%, -113.56 to -43.46$)$ and multigravid $(\mathrm{MD}=-63.46$ minutes, CI $95 \%,-96.88$ to -30.04$)$ women. However, the results are not statistically significant in the subgroup reporting the results in both primi- and multigravid women $(\mathrm{MD}=-$
29.88 minutes, CI 95\%, -111.46 to 51.71). Further, Figure 3 illustrates the Egger's publication bias plot of metaanalysis respecting the effect of hyoscine on the duration of the first stage of labor. Considering the quality of the studies, the results of subgroup analysis reveals that the effect of hyoscine is strong in low-quality studies $(\mathrm{MD}=-$ 72.11 minutes, CI $95 \%,-135.29$ to -8.93$)$ compared to high-quality studies ( $\mathrm{MD}=-61.78$ minutes, $\mathrm{CI} 95 \%$, -76.70 to -46.86). However, there is no evidence concerning the publication bias in studies included in the meta-analysis based on the results of the Egger's test $(P=0.422)$.

\section{Second Stage of Labor}

Figure 4 displays the forest plot of meta-analysis related to the effect of hyoscine on the duration of the second stage of labor. As shown, the total effect of hyoscine on the duration of labor demonstrates a significant difference between the intervention and placebo groups $(\mathrm{MD}=-2.76$

Table 1. Characteristics of Included studies in Systematic Review and Meta-analysis Regarding the Effect of Hyoscine on Labor Duration

\begin{tabular}{|c|c|c|c|c|c|c|c|}
\hline Study & Year & Location & Intervention & Placebo & Parity & Stage of Labor & Quality \\
\hline Al-Khishali (12) & 2009 & Iraq & 50 & 50 & Multigravid/primigravid & First/second/third & Low \\
\hline Jamilian (13) & 2013 & Iran & 54 & 54 & Primigravid & First/second & Low \\
\hline Kirim (14) & 2012 & Turkey & 95 & 85 & Primigravid/multigravid/ Both & First/second/third & Moderate \\
\hline Maged $(7,15)$ & 2016 & Egypt & 40 & 40 & Primigravid & First/second & Moderate \\
\hline Makvandi (16) & 2009 & Iran & 65 & 65 & Primigravid & First/second & High \\
\hline Narappagari (17) & 2015 & Puducherry & 40 & 41 & Primigravid/multigravid & First & Low \\
\hline Qahtani (18) & 2010 & Saudi Arabia & 52 & 45 & Primigravid & First/second & High \\
\hline Samuels (19) & 2005 & Jamaica & 60 & 69 & Both & First & Moderate \\
\hline Sekhavat (20) & 2007 & Iran & 94 & 94 & Multigravid & First/second/third & High \\
\hline Trevino-Salinas (21) & 2010 & Mexico & 43 & 43 & Both & First/second/third & Low \\
\hline
\end{tabular}




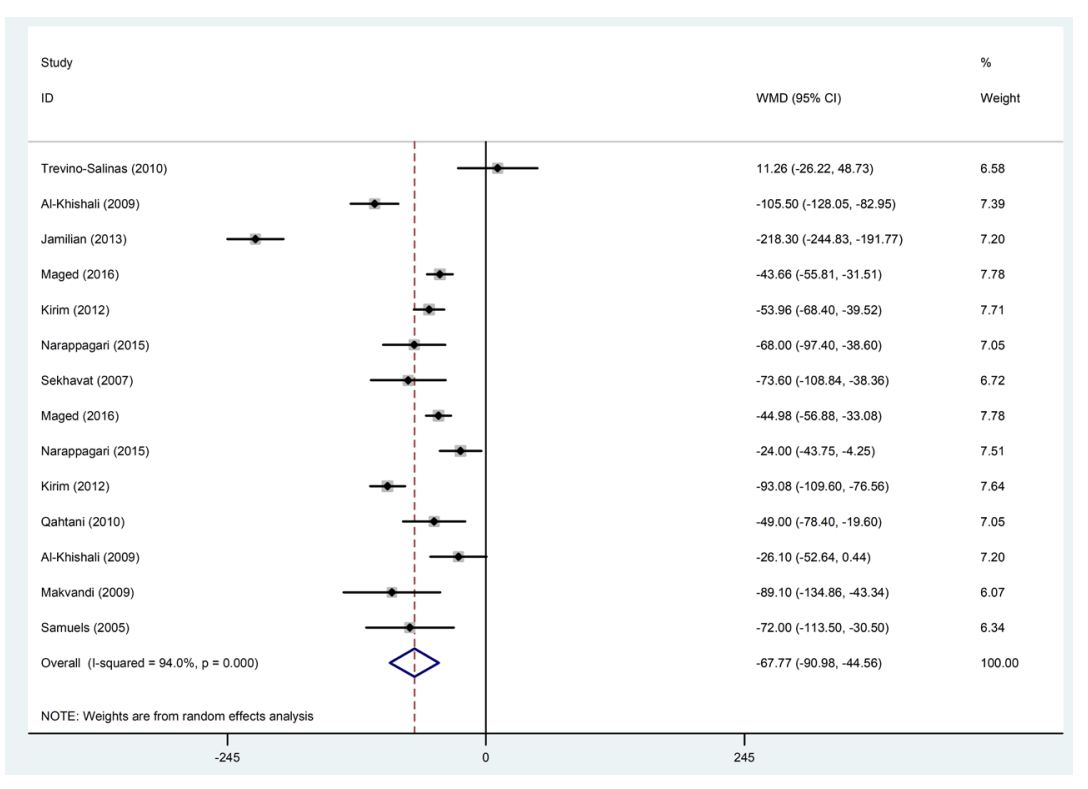

Figure 2. The forest plot of meta-analysis concerning the effect of hyoscine on the duration of the first stage of labor. Note. The size of each square and the lines around it represent the weight of each study and 95\% Cl; WMD: Weighted mean difference.

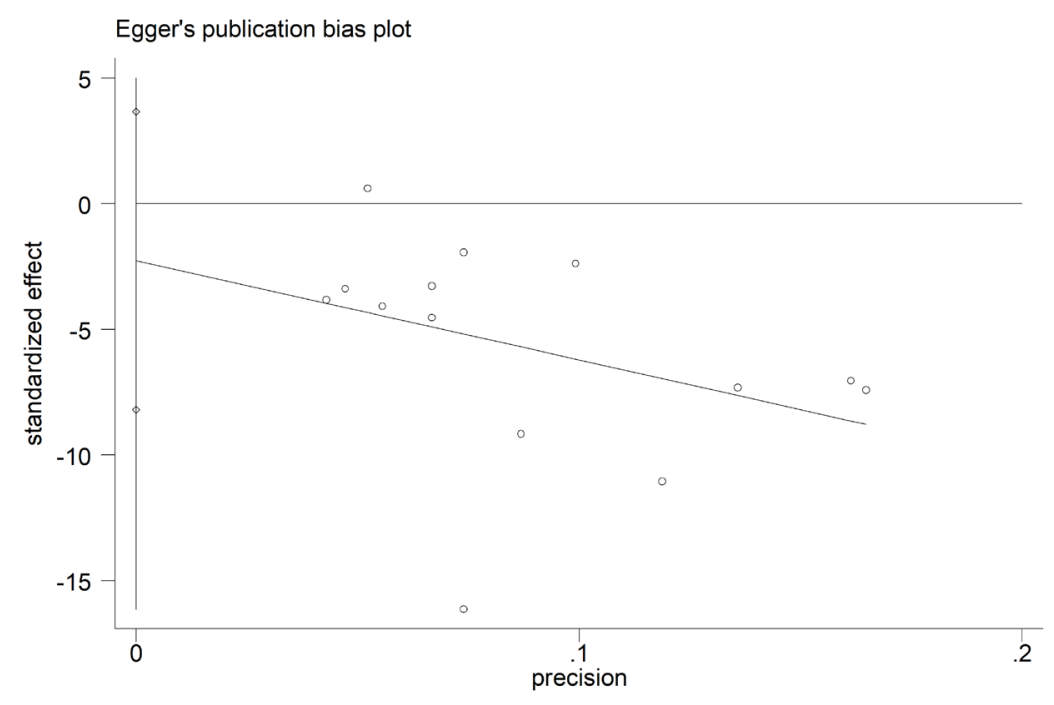

Figure 3. Egger's publication bias plot of meta-analysis respecting the effect of hyoscine on the duration of the first stage of labor.

minutes, CI 95\%, -4.79 to -0.74 ) while not considering the parity status of women. Six out of 10 studies report results in the second stage of labor in primigravid women while two out of 10 studies provide the results related to the second stage of labor among multigravid women. Furthermore, the results of meta-analysis (Figure 5) indicate the significant effect of hyoscine on the reduction of labor duration in the intervention group compared to the placebo group in primigravid women $(\mathrm{MD}=-4.55$ minutes, CI 95\%, -8.74 to -0.35), as well as the subgroup that report the results in both primi- and multigravid women $(\mathrm{MD}=-1.01$ minutes, $\mathrm{CI} 95 \%,-1.82$ to -0.19$)$.
However, the results demonstrate no significant effect in the multigravid women ( $\mathrm{MD}=-2.58$ minutes, CI 95\%, -8.85 to 3.69 ). As regards the quality of studies, the results of subgroup analysis represent the strong effect of hyoscine in high-quality studies ( $\mathrm{MD}=-4.01$ minutes, CI 95\%, -7.20 to -0.81) compared to low-quality studies $(\mathrm{MD}=-1.51$ minutes, $\mathrm{CI} 95 \%,-4.63$ to 1.62$)$. Finally, no publication bias is observed among the included studies in the meta-analysis based on the Egger's test $(P=0.10)$.

Third Stage of Labor

As shown in Figure 6, a significant difference is detected 


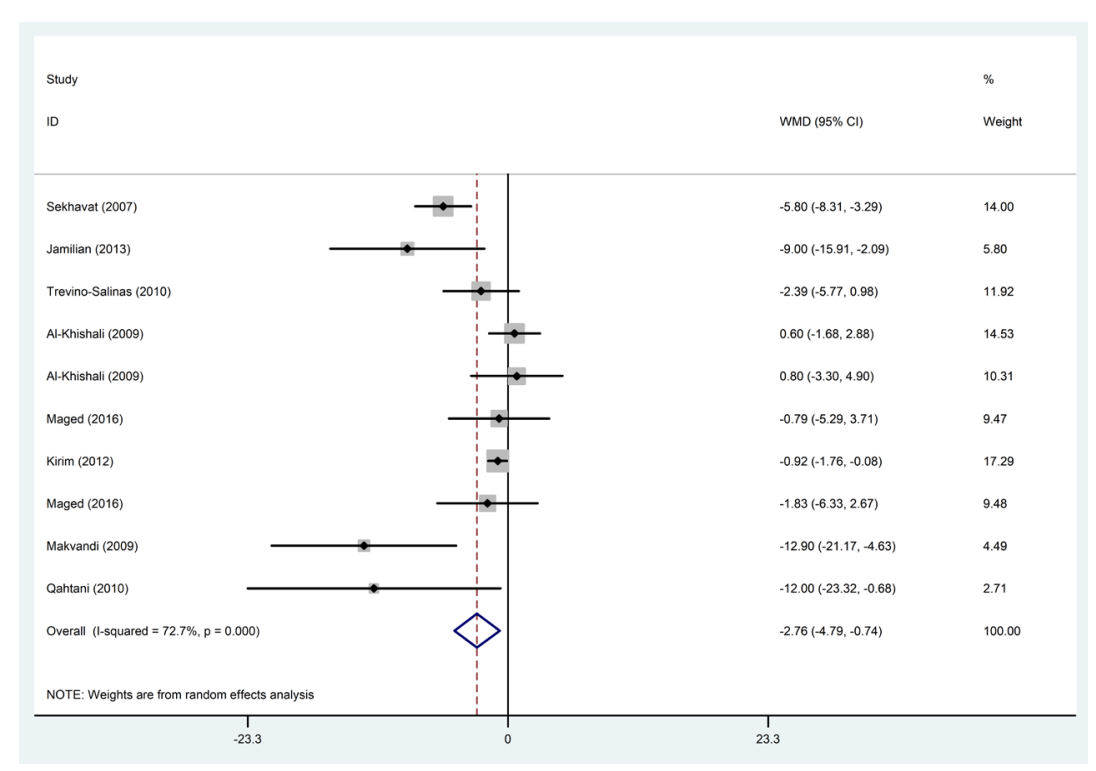

Figure 4. The forest plot of meta-analysis concerning the effect of hyoscine on the duration of the second stage of labor. Note. The size of each square and the lines around it represent the weight of each study and 95\% Cl; WMD: Weighted mean difference.

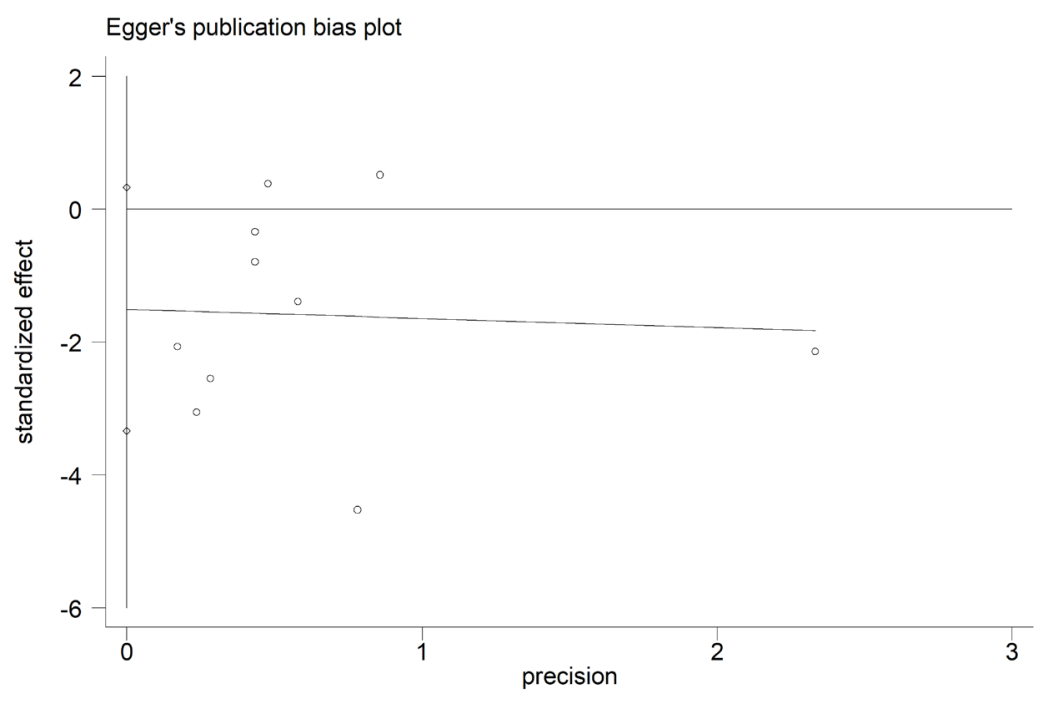

Figure 5. Egger's publication bias plot of meta-analysis respecting the effect of hyoscine on the duration of the second stage of labor.

between the intervention and placebo groups as regards the overall effect of hyoscine on the duration of labor without considering the parity status of women $(\mathrm{MD}=-0.45$ minutes, CI $95 \%,-1.45$ to 0.56 ). Only 5 studies present the results in the third stage of labor. Thus, subgroup analysis is not conducted in this stage as a result of a low number of studies in each group. Based on Figure 7, no evidence of publication bias is found based on the results of the Egger's test ( $P$ 0.430).

\section{Discussion}

Regardless of the parity status of the women, the results of this meta-analysis indicated the significant effect of hyoscine on the reduction of labor duration in the intervention group compared to the placebo group and the average reduction on the duration of labor was 67.77 minutes in the first stage, while it was found to be 2.76 minutes in the second stage. However, the overall effect of hyoscine on labor duration was not significantly different between the intervention and placebo groups in the third stage of labor.

In the systematic review and meta-analysis study reported by Rohwer et al (22), antispasmodics could significantly decrease the mean of overall labor duration 


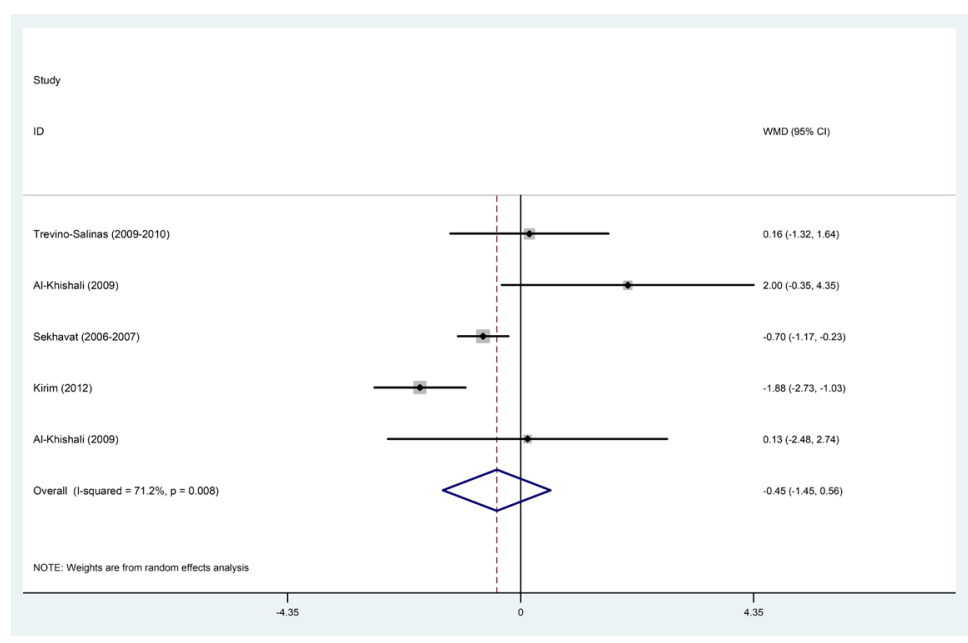

Figure 6. The forest plot of meta-analysis concerning the effect of hyoscine on the duration of the third stage of labor.

Note. The size of each square and the lines around it represent the weight of each study and $95 \% \mathrm{Cl}$; WMD: Weighted mean difference.

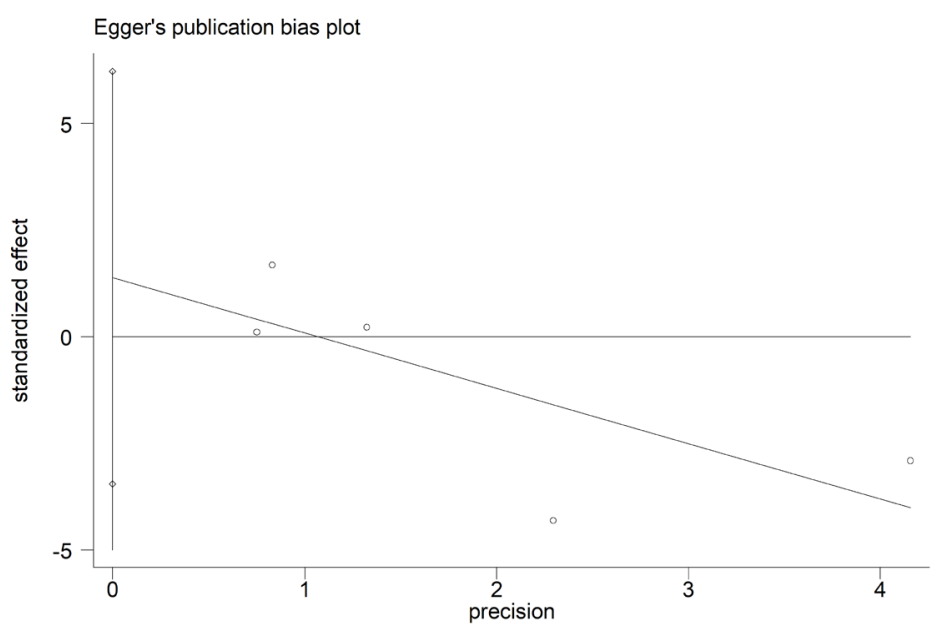

Figure 7. Egger's publication bias plot of meta-analysis respecting the effect of hyoscine on the duration of the third stage of labor.

by 85.51 minutes and the duration of the first stage by an average of 74.34 minutes. Conversely, no significant effect was observed in the second and third stages of labor (22). However, the estimation of Rohwer et al was not suitable to decide on the use of hyoscine since they included all types of antispasmodics while not estimating the separate effect of hyoscine. Moreover, this review encompassed all types of controls (i.e., placebo or no medication), which might have an impact on the effect of hyoscine on the labor duration. In addition, based on parity status, the results related to the subgroup analysis revealed that the strong effect of hyoscine in the first stage of labor in primigravid women whereas no significant effect was found in the second stage of labor among multigravid women. Thus, parity was found to play an important role in the heterogeneity of the results of the current study. Similarly, Al-Khishali et al reported that the experience of multigravida women with normal labor was important in this regard (12).
Based on the results of Ebrahimzadeh Zagami et al. (23), the mean duration of the active phase of labor in the hyoscine group failed to show a significant difference within the control groups. However, this effect was significant for promethazine and thus it was recommended as an effective medication during the labor.

The main limitation of this review was the small number of studies which limited subgroup analysis for exploring the potential source of heterogeneity of the other important variables including the administration routes (i.e., oral, rectal, or IM).

\section{Conclusions}

In general, the findings of the present systematic review and meta-analysis indicated that hyoscine plays a significant role in reducing the duration of labor in the first and second stage of labor. However, no significant effect was observed in the third stage of labor in the intervention group when compared to the placebo 
group. Based on the findings, hyoscine could be used for decreasing the duration of labor in the first and second stage. However, further exploration is required to reach a logical conclusion regarding using hyoscine to reduce labor duration.

\section{Conflict of Interests}

Authors declare that they have no conflict of interests.

\section{Ethical Issues}

The Ethics Committee of Royan Institute approved the proposal of this project (the ethical code: IR.ACECR. ROYAN.REC.1397.34).

\section{Financial Support}

The present research project was financially supported by Royan Institute, Tehran, Iran.

\section{References}

1. Laughon SK, Berghella V, Reddy UM, Sundaram R, Lu Z, Hoffman MK. Neonatal and maternal outcomes with prolonged second stage of labor. Obstet Gynecol. 2014;124(1):57-67. doi:10.1097/aog.0000000000000278

2. Myles TD, Santolaya J. Maternal and neonatal outcomes in patients with a prolonged second stage of labor. Obstet Gynecol. 2003;102(1):52-58.

3. Cheng YW, Hopkins LM, Caughey AB. How long is too long: Does a prolonged second stage of labor in nulliparous women affect maternal and neonatal outcomes? Am J Obstet Gynecol. 2004;191(3):933-938. doi:10.1016/j. ajog.2004.05.044

4. Allen VM, Baskett TF, O'Connell CM, McKeen D, Allen AC. Maternal and perinatal outcomes with increasing duration of the second stage of labor. Obstet Gynecol. 2009;113(6):12481258. doi:10.1097/AOG.0b013e3181a722d6

5. Mollart LJ, Adam J, Foureur M. Impact of acupressure on onset of labour and labour duration: A systematic review. Women Birth. 2015;28(3):199-206. doi:10.1016/j. wombi.2015.03.007

6. Ranjbaran M, Khorsandi M, Matourypour P, Shamsi M. Effect of massage therapy on labor pain reduction in primiparous women: A systematic review and meta-analysis of randomized controlled clinical trials in Iran. Iran J Nurs Midwifery Res. 2017;22(4):257-261. doi:10.4103/ijnmr. IJNMR_109_16

7. Maged AM, Mosaad M, AbdelHak AM, Kotb MM, Salem MM. The effect of hyoscine butylbromide on the duration and progress of labor in primigravidae: a randomized controlled trial. J Matern Fetal Neonatal Med. 2018;31(22):2959-2964. doi:10.1080/14767058.2017.1359828

8. Namazian E, Mokhtari F. The effect of hyoscine in labor process of primiparous women (A Clinical Trial Study). The Iranian Journal of Obstetrics, Gynecology and Infertility. 2017;19(38):57-65. doi:10.22038/ijogi.2017.8282

9. Schulz KF, Altman DG, Moher D. CONSORT 2010 statement: updated guidelines for reporting parallel group randomised trials. BMC Med. 2010;8(1):1-9. doi:10.1186/1741-7015-8-18

10. Moher D, Liberati A, Tetzlaff J, Altman DG. Preferred reporting items for systematic reviews and meta-analyses: the PRISMA statement. PLoS Med. 2009;6(7):e1000097. doi:10.1371/journal.pmed.1000097

11. Higgins JP, Thompson SG, Deeks JJ, Altman DG. Measuring inconsistency in meta-analyses. BMJ. 2003;327(7414):557560. doi:10.1136/bmj.327.7414.557

12. Al-Khishali WAH, Rasheed FA, Hussain SA. The Effect of 20 mg Hyoscine Butylbromide on Normal Labor in Iraqi Primiand Multi-gravida Women. J Adv Sci Res. 2012;3(4):70-73.

13. Jamilian M, Karamali M, Sadeghi B, Ghazi Mirsaeed M. The Effect of Intramuscular Administration of Atropine and Hyoscine Combination on Labor Progress and Maternal and Neonatal Outcomes in Primigravid Women. Iranian Journal of Neonatology. 2016;7(1):13-18. doi:10.22038/ ijn.2016.6659

14. Kirim S, Asicioglu O, Yenigul N, Aydogan B, Bahat N, Bayrak M. Effect of intravenous hyoscine-N-butyl bromide on active phase of labor progress: a randomized double blind placebo controlled trial. J Matern Fetal Neonatal Med. 2015;28(9):1038-1042. doi:10.3109/14767058.2014.942628

15. Ranjbaran M. The effect of hyoscine butylbromide on the duration and progress of labor in primigravidae: a randomized controlled trial: methodological issues. J Matern Fetal Neonatal Med. 2019;32(6):1049. doi:10.1080/ 14767058.2017.1395015

16. Makvandi S, Tadayon M, Abbaspour M. Effect of hyoscine$\mathrm{N}$-butyl bromide rectal suppository on labor progress in primigravid women: randomized double-blind placebocontrolled clinical trial. Croat Med J. 2011;52(2):159-163.

17. Narappagari SR, Himabindu. Effect of hyoscine butylbromide (Buscopan) as cervical spasmolytic agent in labour. J Evol Med Dent Sci. 2016;5(90):6670-6674. doi:10.14260/Jemds/2016/1509

18. Al Qahtani NH, Al Hajeri F. The effect of hyoscine butylbromide in shortening the first stage of labor: A double blind, randomized, controlled, clinical trial. Ther Clin Risk Manag. 2011;7:495-500. doi:10.2147/tcrm.s16415

19. Samuels LA, Christie L, Roberts-Gittens B, Fletcher $\mathrm{H}$, Frederick J. The effect of hyoscine butylbromide on the first stage of labour in term pregnancies. BJOG. 2007;114(12):1542-1546. doi:10.1111/j.14710528.2007.01497.x

20. Sekhavat L, Karbasi SA, Fallah R, Mirowliai M. Effect of hyoscine butylbromide first stage of labour in multiparus women. Afr Health Sci. 2012;12(4):408-411.

21. Trevino-Salinas EM, Castillo-Martin del Campo GC, Ayuzo-Del Valle C, et al. Effect of hyoscine butylbromide on cervical dilation during labor. Medicina Universitaria. 2015;17(66):30-33.

22. Rohwer AC, Khondowe O, Young T. Antispasmodics for labour. Cochrane Database Syst Rev. 2013(6):Cd009243. doi:10.1002/14651858.CD009243.pub3

23. Ebrahimzadeh Zagami S, Golmakani N, Saadatjoo SAR, Dadgar S, Baghbani B. Comparison of effects of hyoscine n-butyl bromide and promethazine on length of active phase of first stage of labor. The Iranian Journal of Obstetrics, Gynecology and Infertility. 2012;15(6):16-21. doi:10.22038/ ijogi.2012.5720

(c) 2019 The Author (s); This is an open-access article distributed under the terms of the Creative Commons Attribution License (http://creativecommons.org/licenses/by/4.0), which permits unrestricted use, distribution, and reproduction in any medium, provided the original work is properly cited. 